\title{
CaMínimo do Açaí: Um jogo para auxiliar no ensino do caminho mínimo em grafos não direcionados
}

\author{
Elias S. Moraes ${ }^{1}$, Maria J. Meninae Duarte ${ }^{2}$, Fabiola P. Oliveira ${ }^{1}$ \\ ${ }^{1}$ Instituto de Ciências Exatas e Naturais (ICEN) - Universidade Federal do Pará (UFPA) \\ 66075-110 - Belém - PA -Brasil \\ ${ }^{2}$ Programa de Pós-Graduação em Estudos Antrópicos na Amazônia (PPGEAA) - \\ Universidade Federal do Pará (UFPA) \\ 68746-360 - Castanhal - PA -Brasil \\ \{eliassm.ufpa, menineamaria\}gmail.com, fpoliveira@ufpa.com
}

\begin{abstract}
This article presents the process of creating, validating, and using the game CaMinimo do Açai. The software in question aims to assist in the teaching and development of computational thinking in school students through the Minimum Path in Non-Directed Graphs. Furthermore, the game addresses the dynamics of the açai harvest, which is the main economic activity in the municipality of Inhangapi, located in the northeast region of Pará where the project was applied. The game development process followed the main steps of software engineering, data collection, and data validation was carried out with students from a high school. After analyzing the data, a positive result was obtained both in the use of the game and in the students' learning about the concept of minimum path and graphs.
\end{abstract}

Resumo. Este artigo apresenta o processo de criação, validação e experiência de uso do jogo CaMinimo do Açaí. O software em questão tem como objetivo auxiliar no ensino e desenvolvimento do pensamento computacional em estudantes em periodo escolar através do Caminho Mínimo em Grafos Não Direcionados. Outrossim, o jogo aborda a dinâmica da colheita do açaí que é a principal atividade econômica do município de Inhangapi, situado na região nordeste do Pará onde o projeto foi aplicado. O processo de desenvolvimento do jogo seguiu as etapas principais da engenharia de software, a coleta de dados e a validação dos mesmos foi realizado junto aos alunos de uma escola de ensino médio. Após a análise dos dados obteve-se um resultado positivo tanto na utilização do jogo quanto no aprendizado dos alunos acerca do conceito de caminho mínimo e grafos.

\section{Introdução}

É indiscutível a influência que as chamadas Tecnologias Digitais de Informação e Comunicação (TDICs) exercem e continuarão a exercer na sociedade. No que tange a educação, por exemplo, cada vez mais as tecnologias digitais vêm sendo utilizadas em sala de aula. Contudo, é necessário implementar meios para que estudantes não se 
limitem a ser meros usuários, mas sim possam também ser provedores de soluções computacionais. Para tal, é preciso que o ensino da computação seja inserido o mais cedo possível, de preferência ainda nos primeiros anos escolares dos estudantes.

De acordo com Almeida (2018), aproximadamente 24 milhões de estudantes de escolas públicas do Brasil têm acesso a TDICs. Segundo um levantamento feito pelo Centro Regional de Estudos para o Desenvolvimento da Sociedade da Informação(2017), cerca de $81 \%$ das instituições de ensino públicas têm laboratórios de informática, entretanto apenas $59 \%$ dos mesmos está em uso e somente $31 \%$ dos professores utilizam esses ambientes para o ensino pedagógico.

Tendo em vista o supracitado, e com o adendo da falta de profissionais qualificados, o ensino da computação em escolas públicas geralmente restringe-se a realização de projetos de curta duração, sendo necessária a implementação de estratégias que contornem as limitações de infraestrutura e de pessoal apto a ensinar. Este trabalho faz um relato da experiência de utilização de uma ferramenta capaz de proporcionar aos estudantes do ensino médio, o contato com o pensamento computacional (PC), através do algoritmo de descoberta do caminho mínimo. Segundo o Currículo de Referência em Tecnologia e Computação (CRTC), o PC tem sido considerado como uma das habilidades fundamentais do ser humano, ao lado da leitura, escrita e aritmética.

A escolha em abordar o caminho mínimo em grafos não direcionados no jogo deu-se em decorrência de haver pouco material que aborde grafos utilizando jogos eletrônicos, e que esse assunto poderia ser contextualizado à dinâmica da colheita do açaí. Outrossim, esse tópico é visto somente no ensino superior, em cursos da área da Computação, o que torna necessário a adoção de mecanismos simplificadores para que este assunto seja compreensível por alunos do ensino médio. Das técnicas existentes para a resolução do problema do caminho mínimo, a mais famosa e empregada é o algoritmo de Dijkstra [Resende 2009] e por isso, esse método foi escolhido e ensinado previamente aos alunos participantes, para que os mesmos pudessem usá-lo como estratégia para solucionar os desafios do jogo.

\section{Metodologia do Trabalho}

A metodologia deste trabalho tem um caráter aplicado, haja vista que o intuito foi desenvolver uma ferramenta que auxiliasse no desenvolvimento do pensamento computacional em alunos do ensino médio. A mesma tem uma característica descritiva, pois foi feita uma pesquisa acerca da cultura, hábitos e características dos moradores de Inhangapi, para que algum aspecto regional fosse inserido no jogo. A avaliação, tanto prévia para analisar o grau de conhecimento dos alunos acerca de assuntos da área da computação, quanto aquela posterior à realização da atividade, que visava mensurar o quanto os participantes aprenderam sobre caminho mínimo e grafos, foram feitas através de questionários de maneira a coletar dados numéricos, para que fosse realizada uma análise quantitativa. Por fim, a pesquisa tem um caráter experimental, já que não há registros da utilização de jogos que auxiliem na prática do PC nas escolas do município onde foi realizado o projeto, bem como no ensino do Caminho Mínimo em Grafos Não Direcionados.

As etapas da metodologia aplicada a esta pesquisa foram as seguintes: levantamento de trabalhos correlatos, prototipação do jogo em papel, visando definir a 
complexidade dos grafos presentes em cada fase do jogo, implementação do códigofonte, aplicação de um questionário antes da utilização da ferramenta para mensurar o conhecimento prévio dos alunos acerca dos assuntos abordados, realização de testes com a ferramenta junto aos alunos, e a aplicação de um questionário pós-projeto para avaliar o jogo e o aprendizado dos alunos. A Figura 1 mostra a ordem de realização das atividades feitas junto aos alunos participantes.

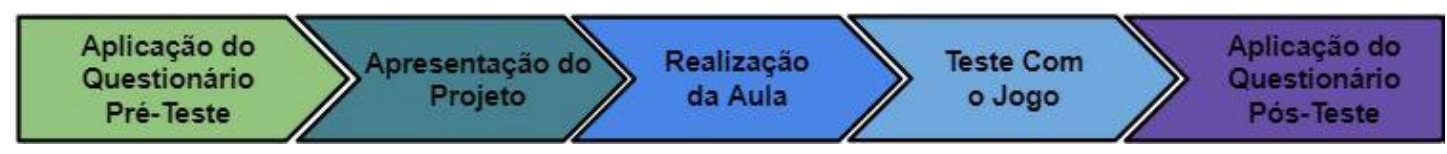

Figura 1. Ordem de realização das atividades do projeto

Os alunos participantes da pesquisa são do ensino médio e foram escolhidos junto a uma professora da escola. Os estudante maiores de idade concordaram em participar voluntariamente dos testes quando assinaram o Termo de Consentimento Livre e Esclarecido (TCLE) e, aqueles menores de idade, levaram o documento para que seus responsáveis pudessem assinar o termo. As atividades do projeto aconteceram no laboratório de informática da escola em dois dias, sendo que no primeiro haviam 2 estudantes e no segundo participaram outros 16. Antes que os alunos tivessem contato com o software, foi ministrada uma aula para explicar os conceitos da Computação abordados no jogo e ensinar o funcionamento do Algoritmo de Dijkstra, informando que essa técnica poderia ser utilizada para encontrar o caminho mínimo nas diversas fases do jogo. Como forma de otimizar o tempo e auxiliar os estudantes que optassem por usar o algoritmo de Dijkstra, foram entregues folhas de papel com tabelas para serem usadas para auxiliar na aplicação do algoritmo. A coluna mais à esquerda de cada tabela continha o números de vértices dos grafos representados nas fases do jogo. Na linha superior das tabelas estavam descritas a quantidade de etapas (passos) que seriam necessárias para a resolução de cada um dos algoritmos. O objetivo era que o alunos usassem as tabelas para aplicar o passo a passo do algoritmo da mesma forma que foram ensinados na aula.

Pela limitação de infraestrutura do laboratório, os alunos foram divididos em duplas, ficando cada uma delas em um computador. Durante as atividades, os autores desta pesquisa foram sanando dúvidas de alguns alunos sobre conceitos abordados e a utilização do jogo. Vale destacar que a maioria dos alunos envolvidos são oriundos da zona rural do referido município.

\section{Trabalhos correlatos}

Existem diversos trabalhos que visam a utilização de jogos eletrônicos como estratégia de ensino e desenvolvimento do pensamento computacional. Todavia, ao ser feito um levantamento literário, verificou-se que tais estudos não tratam do conceito de caminho mínimo em grafos e tão pouco têm a preocupação de abordar nos jogos elementos do cotidiano do público alvo das pesquisas.

Marques et al. (2016) propõem um jogo composto por quatro mini jogos, onde cada um desses têm o objetivo de apresentar um conceito da área da computação. Os autores optaram por utilizar temas comuns como base para a dinâmica de cada mini jogo. Com o intuito de ensinar o conceito da Máquina de Turing, Pires et al. (2019) apresentam uma proposta de jogo de estratégia baseado em puzzles para desenvolver o 
pensamento computacional. O jogo apresenta como tema e enredo a lenda do Curupira, entretanto os autores desenvolveram apenas protótipos do jogo, o que inviabilizou os testes com a ferramenta proposta.

Para abordar conceitos como coloração de grafos e ordenação, Michel et al. (2019) desenvolveram um jogo estilo tower defense, onde o objetivo é defender-se do ataque inimigo posicionando as peças disponíveis de forma estratégica. A abordagem do pensamento computacional é feita de maneira implícita, ademais, os autores não relatam testes com a ferramenta.

\section{Construção do software}

\subsection{Modelagem do jogo CaMínimo do Açaí}

Segundo Nakagawa (2015), caso de uso trata-se de uma unidade funcional do sistema manifestada por uma sequência de mensagens entre sistema e um ou mais atores (usuários ou outros sistemas). Ainda segundo a autora, o caso de uso representa uma utilização do sistema que pode ser feita por um ator, que pode ser uma pessoa, dispositivo ou mecanismos que interagem com o sistema. A Figura 3 apresenta o diagrama de casos de uso do CaMínimo do Açaí. A mesma imagem mostra que o software possui o ator "jogador" e que esse pode iniciar uma partida do jogo, movimentar o personagem pelo cenário e pular os diálogos que aparecem na tela.

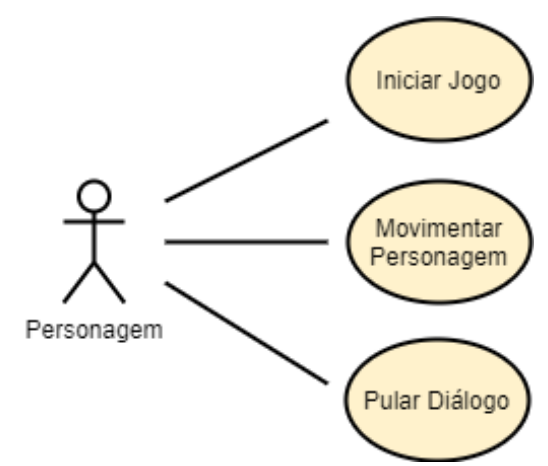

Figura 3. Diagrama de Casos de Uso do jogo CaMínimo do Açaí

De acordo com Dias et al. (2006), o que diferencia um diagrama de classes de um fluxograma é a possibilidade de representar atividades concorrentes, com execuções em paralelo. Outrossim, esse diagrama é composto por raias de responsabilidade que representam onde cada atividade será executada [Dias et al. 2006]. A Figura 4 mostra o diagrama de atividades que compõem o CaMínimo do Açaí. A mesma mostra as atividades desempenhadas pelo jogador, no caso, iniciar o jogo e movimentar o personagem por um dos caminhos. Quanto às ações do sistema, é possível ver que o mesmo verifica se o caminho está correto. Caso esteja correto, deve informar ao usuário e iniciar uma nova etapa, se não estiver, indica isso ao usuário e reinicia a fase. 


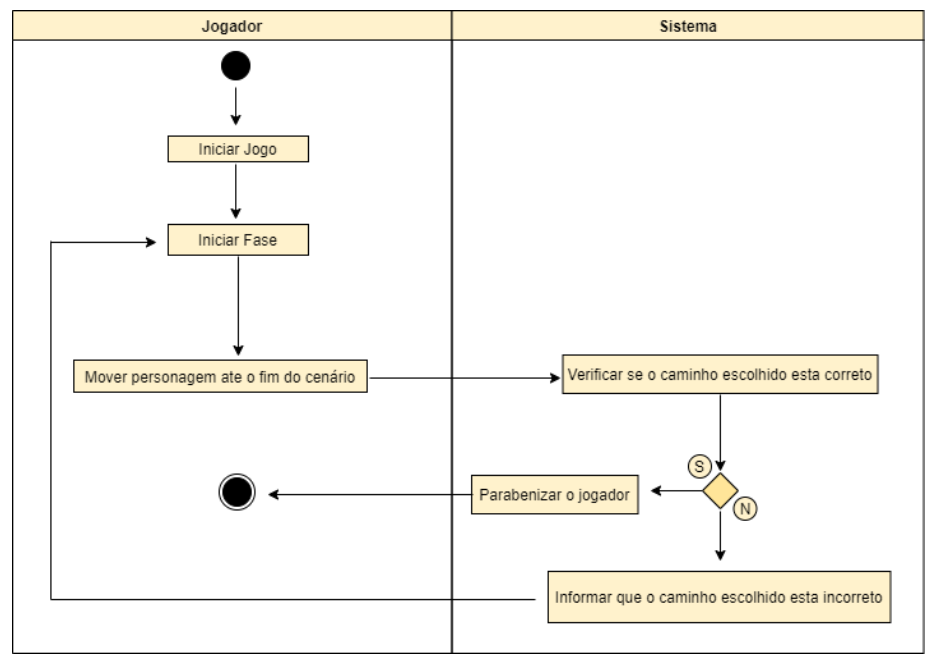

Figura 4. Diagrama de Atividades do CaMínimo do Açaí.

\subsection{Prototipação}

Segundo Rosemberg et al. (2008), um protótipo "é uma representação limitada de um design, o qual pode ser um esboço em papel de uma tela ou um conjunto de telas[...]". Os protótipos podem ser feitos de diversas formas e em diversas ferramentas, desde uma folha de papel, como citado anteriormente, até um software de modelagem 3D.

Durante o desenvolvimento do CaMínimo do Açaí foram feitos dois protótipos: um em papel (baixa fidelidade) e outro no Construct 2. O primeiro tinha como objetivo mensurar e definir a complexidade dos grafos que compõem cada fase do jogo, já o segundo visava testar as possibilidades de movimentação de objetos em um cenário feito no Construct 2. A Figura 5 mostra os dois protótipos desenvolvidos.

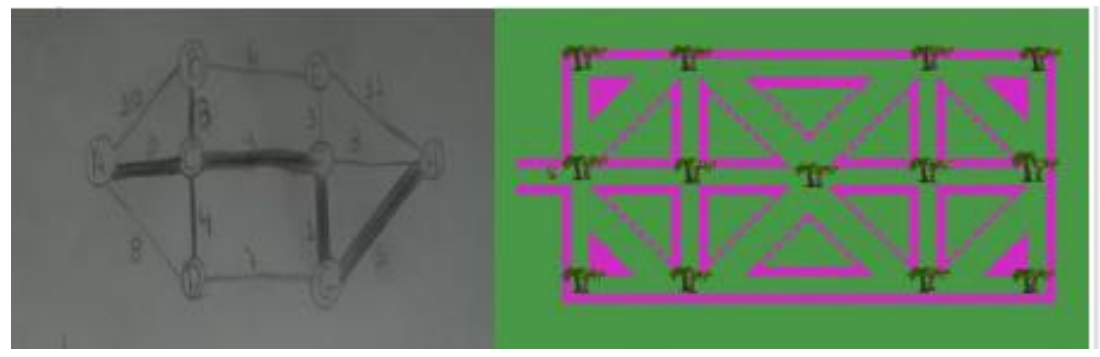

(a)

(b)

Figure 5. Protótipo feito em papel (a) e no Construct 2 (b)

Após a fase de prototipação deu-se início a modelagem das telas do jogo e posteriormente a codificação do mesmo. As duas etapas citadas foram realizadas no Construct 2. Na tela inicial do jogo é encontrado em maior dimensão as imagens das palmeiras que representam os vértices. Há também o título do jogo, bem como a mensagem "Aperte ENTER para começar" indicando que o usuário pode iniciar o jogo quando quiser.

\section{CaMínimo do Açaí}

A proposta da aplicação CaMínimo do Açaí é ser uma ferramenta de inclusão capaz de ensinar o conceito de caminho mínimo em grafos não direcionados e ajudar na prática 
do pensamento computacional em alunos de escolas públicas com pouca infraestrutura. A ferramenta também visa despertar o interesse e uma identificação maior dos alunos de Inhangapi com os elementos encontrados no software, levando o contexto da colheita do açaí, que faz parte do cotidiano dos estudantes, para dentro do jogo.

Como pontuado anteriormente, a codificação do CaMínimo do Açaí ${ }^{1}$ foi realizada no software Construct 2. Essa ferramenta desenvolvida pela Scierra Ltda, é baseada em HTML5 e é destinada a programadores e não programadores, permitindo ao usuário desenvolver jogos multiplataforma em 2D [Scierra 2019]. A escolha por esse motor gráfico deu-se pelo mesmo ser de fácil e rápido manuseio, ter uma versão gratuita atende as necessidades do jogo, ter uma comunidade grande e ativa na internet e por permitir o desenvolvimento de aplicações que podem ser executadas em diversos navegadores.

O jogo é constituído de objetos e entidades com duas dimensões (2D) e uma visão em terceira pessoa do personagem principal. Em sua versão estável o jogo possui 3 fases, com dificuldade crescente que são acessadas de acordo com a progressão do jogador. A cada nível ultrapassado são adicionadas mais palmeiras e caminhos (arestas) possíveis de serem percorridos, o que faz com que a complexidade do algoritmo, que serve de base para fase, aumente. O contexto da colheita do açaí está inserido tanto no cenário das fases quanto na lógica de resolução do caminho mínimo.

A fase 1 do jogo é composta por 8 palmeiras e 13 caminhos. Na fase 2, o grafo representado é formado por 13 palmeiras e 23 caminhos. A terceira e última fase do jogo é constituída de 19 palmeiras e 34 caminhos. Vale lembrar que as palmeiras representam vértices e os caminhos são as arestas de cada grafo representado.

O jogo é composto por 6 telas (inicial, tela de mensagem, fase 1, fase 2, fase $3 \mathrm{e}$ notificação de conclusão de todas as fases). Além das telas, o jogo contém uma caixa de diálogo que, dependendo da etapa em que o usuário se encontra, apresenta uma mensagem diferente, com textos que abordam as características do município de Inhangapi, explicações sobre os assuntos abordados no jogo, seu propósito, os controles e comandos necessários para a utilização do mesmo. Nota-se que os trajetos entre as palmeiras é composto por números que representam os pesos (valores) das arestas do grafo. O objetivo principal do jogo é levar o personagem do ponto de partida até a palmeira localizada na saída do terreno, simulando as rotas percorridas pelos indivíduos conhecidos como apanhadores de açaí, e isso deve ser feito visando o trajeto onde a somatória dos valores dos caminhos seja a menor possível. Durante sua movimentação, o personagem vai demarcando o trajeto percorrido, como ilustrado na Figura 6.

Após a conclusão das três fases, o sistema apresentará um tela informando que o usuário concluiu todos as etapas do jogo. Nela está escrito a frase "Parabéns! Última etapa Concluída" e o sistema mostrará o número de tentativas feitas pelo jogador e o tempo que o mesmo levou para concluir as todas as etapas do jogo.

\footnotetext{
${ }^{1}$ Link do jogo CaMínimo do Açaí:

https://drive.google.com/drive/folders/1pmzctfRa1w_iXblRCX5PmRE4craJ4Z0C?usp=sharing
} 


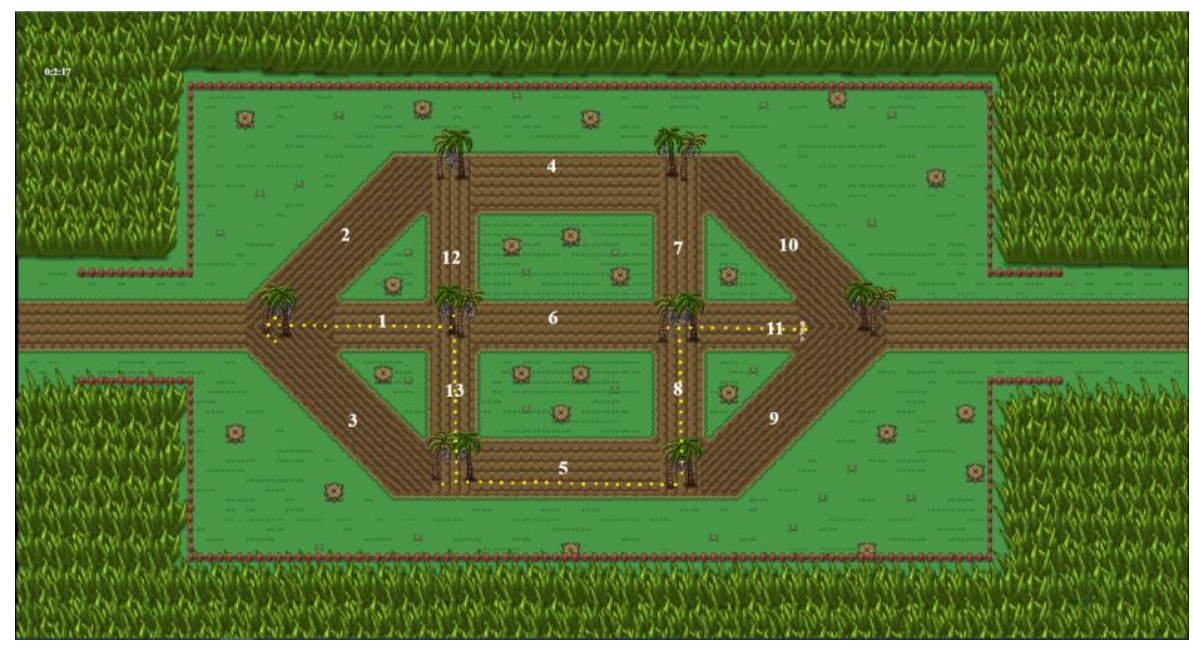

Figura 6. Fase 1 e demarcação do caminho percorrido

\section{Resultados}

No total, participaram deste trabalho 18 alunos do ensino médio e notou-se durante a utilização do jogo que a maioria dos alunos usou tanto o algoritmo de Dijkstra quanto a tabela de apoio para a resolução principalmente da primeira fase do jogo. Porém, a medida que o tempo da atividade foi chegando ao fim e com o aumento na complexidade das fases seguintes, os participantes tiveram maiores dificuldades e isso levou os mesmos a usarem a estratégia de tentativa e erro para poderem completar a maior parte das fases do jogo.

\subsection{Resultado do questionário pré-projeto}

O primeiro questionário aplicado era composto por 16 perguntas, divididas em duas partes, com 8 perguntas cada. A parte inicial abordava os aspectos socioeconômicos dos participantes e tinha o objetivo de traçar um perfil mais preciso desses indivíduos. Já a segunda focava em perguntas referentes a familiaridade e o acesso dos alunos às TDICs, além de questionar o conhecimento prévio dos participantes sobre conceitos da Computação, como pensamento computacional e grafos.

Ao analisar as informações obtidas pelo questionário, constatou-se que 27,8\% dos entrevistados eram do sexo masculino e que 72,2\% eram do sexo feminino. Quanto a idade, percebeu-se que mais de $72 \%$ dos alunos tinham entre 17 e 18 anos. Quando perguntados ondem tinham cursado o ensino fundamental, 77,8\% dos alunos disseram que foi totalmente em escolas públicas, enquanto que 22,2\% responderam que parte foi em escolas públicas. Quanto ao questionamento se pretendiam realizar o Exame Nacional do Ensino Médio (ENEM), 88,8\% responderam que sim, 5,6\% disseram não e outros 5,6\% não souberam opinar. No que tange ao interesse em cursar uma faculdade $94,4 \%$ disseram sim e 5,6\% responderam não. Contudo, quando foi perguntado qual cursos os alunos gostariam de fazer, nenhum aluno demonstrou interesse pela área da Computação. Uma possível explicação para isso é que os alunos não têm contato frequente como computador e nem informações mais aprofundadas sobre a área.

Feito o levantamento dos dados da segunda parte do questionário, notou-se que ao serem perguntados se possuem aparelhos tecnológicos em casa, 55,6\% dos alunos disseram possuir smartphone, 88,9\% têm televisores e apenas $11,1 \%$ afirmam ter 
computador. Vale ressaltar que para essa pergunta foi permitido a escolha de mais de uma opção. Quando questionados se gostam de usar aparelhos como computador, celular, entre outros, $100 \%$ dos alunos disseram que sim, sendo que destes, $55,6 \%$ utilizam essas ferramentas para pesquisas escolares, e os outros $44,4 \%$ para outros tipos de pesquisas e atividades. Perguntados se têm acesso à Internet e quanto tempo passam acessando, 72,2\% dos alunos, ou seja, quase três quartos do total afirmaram usar Internet no máximo 5 horas por dia, 16,7\% entre 5 e 10 horas e 11,1\% disseram não ter acesso à Internet. Outro dado extraído do questionário é referente ao local onde os alunos mais acessam à Internet. Os resultados indicaram que 16,7\% acessam em casa, 44,4\% usam a Internet da escola, 11,1\% usam a Internet da rede pública disponibilizada por um programa do Estado e 27,8\% acessam pela internet de terceiros. Vale pontuar que o resultado desta pergunta mostra que a maior parte dos estudantes não têm acesso a Internet em casa. Uma explicação para isso é o fato de que os alunos, em sua maioria, são moradores da zona rural, onde o acesso à Internet limita-se basicamente ao uso de celulares. Quando perguntados se sabiam o que era PC, 55,5\% responderam que provavelmente sabiam do que se trata, 33,3\% disseram que possivelmente não sabem e $11,1 \%$ afirmaram não saber. Sobre o contato com os assuntos relacionados a grafos e caminho mínimo, cerca de 38,9\% acreditam já ter tido algum tipo de conhecimento sobre esses conceitos durante as atividades escolares, $16,7 \%$ disseram que provavelmente não tiveram contato e $44,4 \%$ afirmaram que nunca tiveram nenhuma relação com esses assuntos. Esse resultado pode ser explicado pelo fato de que assuntos relacionados ao PC não são ensinados na grande maioria das escolas (públicas e nem privadas) do país, e em escolas distantes de grandes centro, o contato dos alunos com determinados conceitos é ainda mais difícil.

Ao serem perguntados se cursariam alguma graduação na área da Computação, a resposta de $83,4 \%$ dos alunos foi positiva, enquanto que $16,6 \%$ disseram que provavelmente não cursariam. A última pergunta do primeiro questionário tinha como objetivo saber se os estudantes acreditavam que conceitos da área da computação e das tecnologias poderiam ser utilizados no ensino básico e no cotidiano das pessoas. Observou-se que $100 \%$ dos entrevistados deram uma resposta positiva quanto a pergunta.

\subsection{Resultado do questionário pós-projeto}

Após a realização das atividades do projeto foi distribuído a cada um dos estudantes outro questionário. $\mathrm{O}$ documento era composto por dez perguntas elaboradas com o objetivo de identificar o grau de satisfação dos alunos após as atividades. Outro ponto importante levantado no questionário foi a impressão dos alunos acerca da utilização do CaMínimo do Açaí. Dos entrevistados, 55,6\% concordam totalmente com afirmativa de que o material didático usado no projeto foi suficiente, $33,3 \%$ demonstraram-se neutros e $11,1 \%$ discordaram. Sobre o jogo ter uma linguagem simples, dinâmica e de fácil entendimento, $22,2 \%$ dos alunos concordaram totalmente, $72,2 \%$ concordam e $5,6 \%$ ficaram neutros. Os alunos também indicaram se os assuntos expostos durante a apresentação do projeto auxiliaram na utilização do jogo. As respostas apontam que $78,2 \%$ tiveram impressões positivas quanto a isso.

Quando perguntados se a progressão da dificuldade entre uma fase e outra do jogo estava adequada, $100 \%$ dos entrevistados deram uma resposta positiva. Houve também impressões $100 \%$ positivas sobre outras duas afirmativas do questionário: uma 
era a que os conceitos da computação quando relacionados ao cotidiano facilitam a aprendizagem, e a outra era que as atividades do projeto mostraram com eficiência a importância do estudo do caminho mínimo em grafos e onde o mesmo pode ser empregado. Entretanto deve-se ressaltar que a primeira afirmativa foi baseada na opinião dos alunos, necessitando assim de comprovação através de outros testes que ratifiquem a eficacia no processo de aprendizagem quando a computação esta relacionada a elementos do cotidiano.

Quanto à afirmativa de que o jogo cumpre com o seu objetivo de auxiliar no entendimento do que é caminho mínimo em grafos não direcionados, 22,2\% concordam totalmente, $72,2 \%$ concordam e 5,6\% ficaram neutros. Ao se depararem com a afirmativa de que o jogo consegue retratar bem alguns aspectos do seu município, $88,9 \%$ dos alunos deram respostas positivas e $11,1 \%$ se mantiveram neutros. Vale ressaltar que não houve opiniões negativas quanto às representações do cotidiano dos alunos feitas no jogo.

O tempo médio que cada uma das duplas precisou para concluir as três fases do jogo ficou em torno de 30,05 minutos. Quanto ao número de tentativas necessárias para concluir o jogo, a média ficou em 13 para cada dupla.

\section{Conclusão}

Este projeto gerou resultados positivos junto aos alunos participantes, entre os quais estão: a identificação dos alunos com os elementos regionais presentes no jogo, um maior interesse pela área da Computação ao final das atividades, um bom entendimento sobre o que é pensamento computacional, grafos e caminho mínimo. Vale destacar que outro ponto muito positivo foi que durante a apresentação do projeto e a utilização do jogo, os alunos levantaram possíveis usos do conceito de caminho mínimo em grafos para solucionar problemas do cotidiano dos habitantes de Inhangapi, como por exemplo criar estratégias para um escoamento mais eficiente da produção agrícola do município.

Destaca-se também que do total de alunos, 94,4\% dos mesmos expressaram concordar com a afirmativa de que o jogo auxilia no entendimento de grafos e caminho mínimo e o restante se disse neutro, não havendo portanto opiniões negativas quanto a eficiência do software em seu objetivo pedagógico. Entretanto, o jogo ainda necessita de melhorias, entre as quais está a implementação da obrigatoriedade da resolução do algoritmo de Dijkstra para o avanço nas fases, a inserção de um banco de dados no jogo para coletar as informações de cada partida realizada, melhorar o sistema de movimentação do personagem, entre outras. Todos os ajustes citados serão realizados futuramente e após isso novos testes serão realizados com outro grupo de alunos.

Por fim, esta pesquisa disponibiliza uma opção digital lúdica para o ensino de grafos e caminho mínimo, e coloca em evidência a importância de inserir elementos do cotidiano dos indivíduos no processo de ensino e aprendizagem, e isso pode ser apontado pelo fato de que $100 \%$ dos alunos concordaram com a afirmativa de que relacionar conceitos da computação ao cotidiano facilita na aprendizagem. Tal concordância está em conformidade com o principal diferencial entre este trabalho e seus correlatos, que no caso é a inserção de elementos comuns a vivência dos alunos no jogo, para que os mesmos pudessem ter uma maior identificação e interesse ao utilizar a ferramenta, e por consequência uma maior facilidade em assimilar os conceitos da computação contidos na mesma. 
IX Congresso Brasileiro de Informática na Educação (CBIE 2020)

Anais do XXVI Workshop de Informática na Escola (WIE 2020)

\section{Referencias}

Almeida, Helber Rangel Formiga Leite de. "O Uso das Tecnologias Digitais da Informação e Comunicação na Aula de Cálculo 1 a Distância”. 2013. Disponível em:http://www.rc.unesp.br/gpimem/downloads/artigos/autores/almeida_ebrapem2013.pdf.

Acesso em: 25 de Out. 2019

Centro Regional de Estudos Para O Desenvolvimento da Sociedade da Informática. "Cetic.br pesquisa o uso de celular por alunos para a realização de atividades escolares". 2017. Disponível em: <https://cetic.br/noticia/cetic-br-pesquisa-o-uso-de-celular-por-alunos-paraa-realizacao-de-atividades-escolares/>. Acesso em: 26 de Out. de 2019

CURRÍCULO DE REFERÊNCIA EM TECNOLOGIA E COMPUTAÇÃO (CRTC). Disponível em: <https://curriculo.cieb.net.br/assets/docs/Curriculo_de_Referencia_em_ Tecnologia_e_Computacao.pdf>. Acesso em 19 Jun. 2020.

Dias, Felipe et al. "Uma Abordagem para a Transformação Automâtica do Modelo de Negócio em Modelo de Requisitos". Disponível em: <http://wer.inf.pucrio.br/WERpapers/artigos/artigos_WER06/dias.pdf $>$. Acesso em 08 de Jul. 2020

Marques, Leonardo et al. "Conhecendo a Computação através de jogos". 2016. Disponível em: http://www.sbgames.org/sbgames2016/downloads/anais/157401.pdf. Acesso em 21 de Jul. 2019

Michel, Fabio et al. "WAlgor: um jogo de tower defense para o desenvolvimento do Pensamento Computacional e apresentação de algoritmos computacionais". 2019. Disponível em: https://www.br-ie.org/pub/index.php/wcbie/article/view/8993/6542. Acesso: 20 de Jul. 2019.

Nakagawa, E. Y. "Casos de Uso e Diagrama de Casos de Uso". 2015. 31 slides. Disponível:https://edisciplinas.usp.br/pluginfile.php/3720765/course/section/857581/Aula02 _CasosDeUso.pdf. Acesso em 08 de Jul.2020.

Pires, Fernanda et al. Desenvolvendo o Pensamento Computacional através da Máquina de Turing: o enigma do Curupira. 2019. Disponível em: $<$ https://sol.sbc.org.br/index.php/wei/article/view/6657/6553>. Acesso em: 29 out. 2019.

Rosemberg, C., Schilling, A., Bastos C. and Araripe, R. (2008) "Prototipação de Software e Design Participativo: uma Experiência do Atlântico", https://www.researchgate.net/profile/Carlos_Carvalho10/publication/220737394_Prototipac ao_de_software_e_design_participativo_uma_experiencia_do_atlantico/links/5c984bc59285 $1 \mathrm{cf0ae} 95 \mathrm{ecbc} /$ Prototipacao-de-software-e-design-participativo-uma-experiencia-doatlantico.pdf. Acesso em: 08 de Jul. de 2020.

Sierra. (2019). "Construct 2". Disponivel em: https://www.scirra.com/. Acesso em: 20 de Fev. 2019.

Teófilo, L. and Resende, B. A. (2009) "Introdução a rede de computadores". Disponível em: https://pt.scribd.com/document/54050346/Algoritmo-de-Dijkstra. Acesso em: 16 de Jul. 2020. 